\title{
Bitkisel Esaslı Kesme Yağına Nano Grafit İlavesinin Viskozite ve Termal
} İletkenlik Üzerindeki Etkileri

\author{
${ }^{* 1}$ Şenol ȘiRİN, ${ }^{2}$ Turgay KIVAK, ${ }^{3}$ Çağrı Vakkas YILDIRIM, ${ }^{4}$ Emine ȘiRİN and ${ }^{5}$ İlyas UYGUR \\ ${ }^{*}$ Düzce Üniversitesi Gümüssova MYO, Makine ve Metal Teknolojileri Bölümü, Düzce, Türkiye \\ ${ }^{2}$ Düzce Üniversitesi Teknoloji Fakültesi, Makine ve İmalat Mühendisliği Bölümü, Düzce, Türkiye \\ ${ }^{3}$ Erciyes Üniversitesi, Havacılık ve Uzay Bilimleri Fakültesi, Uçak Gövde-Motor Bölümü, Kayseri, Türkiye \\ ${ }^{4}$ Düzce Üniversitesi Gümüşova MYO, Makine ve Metal Teknolojileri Bölümü, Düzce, Türkiye \\ ${ }^{5}$ Düzce Üniversitesi Mühendislik Fakültesi, Makine Mühendisliği Bölümü, Düzce, Türkiye
}

\section{Özet:}

Son yıllarda, nanoakışkanlar üzerine yapılan çalışmaların ortaya çıkmasıyla, nanoteknolojik soğutma terimi kullanılmaya başlanmıştır. Nanoakışkanlar, içeriğinde bulunan ve çok düşük oranlarda $(<$ hacimce \%1) eklenen nanopartiküllerin yüksek termal iletkenliklerinden dolayı, 1sı transfer özelliklerini önemli oranda arttırmaktadırlar. Nanoakışkanlar, yakıt hücreleri, hibrid motorlar, termal mıknatıslar gibi cihazlarda ve tornalama, frezeleme, metal işleme gibi geniş kullanım alanına sahiptirler. Grafit doğada bulunabildiği gibi kristal yapısındaki hareketli elektronlar yüzünden elektriği de iyi iletebilmektedir. $\mathrm{Bu}$ çalışmada; bitkisel esaslı yağ içerisine hacimce $\% 0,25-0,50-0,75$ ve 1,00 oranlarında, ortalama $80 \mathrm{~nm}$ boyutlarında nanografit tozları eklenmiştir. Nanoakışkan karışımlar mekanik karıştırıcı, ultrasonik homojenizatör ve manyetik karıştırıcıyla hazırlanmıştır. Farklı oranlarda hazırlanan nanoakışkanların viskozite ve termal iletkenlikleri incelenmiş ve bitkisel esaslı yağa eklenen grafit nanopartiküllerin termal davranışları ortaya konmuştur. Sonuç olarak baz bitkisel esaslı yağa eklenen farklı oranlardaki nano grafit partikülleri viskozite ve termal iletkenlikte artışa neden olmuştur, katkı oranlarının artmasıyla çok fazla bir artışın olmadığı görülmüştür.

Anahtar kelimeler: Grafit, Nanoakışkan, Termal iletkenlik, Viskozite

\section{Investigation of Viscosity and Thermal Conductivity of Vegetable Based Nanofluid with Nano Graphite Additive}

\begin{abstract}
:
In recent years, nanotechnological cooling has begun to be used as a result of studies on nanofluids. Nanoparticles significantly increase their heat transfer properties due to their high thermal conductivity of the nanoparticles present in their contents and added at very low rates ( $<\% 1$ volume). Nanofluids have a wide range of applications such as fuel cells, hybrid motors, thermal magnets and turning, milling etc. Graphite can be found in nature as well as electrics due to the moving electrons in the crystal structure. In this study; average $80 \mathrm{~nm}$ nanographite powders were added in the vegetable oil at the ratio of 0.25 0.50-0.75 and $1.00 \%$ vol. Nanofluid mixtures were prepared with mechanical stirrer, ultrasonic homogenizer and magnetic stirrer. Viscosity and thermal conductivity of nanofluids prepared at different ratios were investigated and the thermal behaviors of graphite nanoparticles added to vegetable based oil have been revealed. As a result, viscosity and thermal conductivity increase in base vegetable oil with added nano graphite particles at different ratios but there is no significant increase due to the increase of the additive ratios.
\end{abstract}

Key words: Graphite, Nanofluid, Thermal conductivity, Viscosity

*Corresponding author: Address: Department of Machine and Metal Technology, Gumusova Vocational School Duzce University, 81850, Duzce TURKEY. E-mail address: senolsirin@duzce.edu.tr, Phone: +903807312045 


\section{Giriş}

Isı transferi; havalandırma sistemlerinden yakıt hücrelerine, güç sistemlerinden metal işleme proseslerine kadar birçok alanda önemli bir rol oynamaktadır [1]. Katı haldeki nanopartiküllerin su, yağ ve Etilen Glikol (EG) gibi sıvıların içine karıştırılmasıyla oluşan nanoakışkanlar, termal iletkenlik özelliklerine olumlu katkı sağladıklarından, üzerine yapılan çalışmalar son yıllarda artış göstermektedir [2,3]. Sıvıların termal iletkenliğini arttırmanın en etkili yolu, küçük boyutlarda olan katı parçacıkları ekleyerek transfer özelliklerini değiştirmektir [3]. Fakat eklenen nanopartiküller sıvı içerisinde topaklanma, stabilitede zayıflama, akışkanlıkta azalma gibi olumsuz durumlar oluşturabilmektedir [4-6]. Nanoakışkanlarda, stabilitede sürenin uzun olması, düşük maliyet ve iyi akışkanlık, 1sı transferi uygulamalarında kullanılan en önemli üç parametredir [3].

Yapılan çalışmalarda nanoakışkanların termal iletkenliğini arttırmada nispeten diğer partiküllere göre fazla kullanılan nanopartiküller, oksit esaslılardır [7,8]. Ancak oksit nanopartiküllere ek olarak, kullanımı yaygın olan diğer nanopartiküller; metaller, nitritler ve karbon nanotüplerdir [9]. Nanoakışkanlar kullanılarak yapılan çalışmaların büyük bir bölümü, akışkanın termal iletkenlik katsayısını ve nanopartikül eklenerek elde edilen termal transfer artışı üzerine yoğunlaşmaktır [10]. Saf sıvıya eklenen katı nanopartiküllerin katkı oranı arttıkça oluşan nanoakışkanın viskozitesinde de artış meydana gelmektedir [11]. Nanoakışkanların kullanılabilirliklerinin incelenmesi bir başka ifadeyle nanopartikül katkılı nanoakışkanın saf sıvıya göre avantajlarının değerlendirilmesi, termal iletkenlik katsayısının tespiti ve viskozite ölçülmesiyle daha sağlıklı olmaktadır [12].

$\mathrm{Bu}$ çalışmada, metal kesme işlemlerinde kullanılan bitkisel esaslı yağa ortalama $80 \mathrm{~nm}$ boyutlarında nano grafit partikülleri eklenerek hazırlanan nanoakışkanın, viskozite ve termal iletkenlikleri ölçülmüştür. Baz bitkisel esaslı yağa farklı karışım oranlarında eklenen nano grafitin, vizkozite ve termal davranışlarına olan etkileri araştırılmıştır.

\section{Malzeme ve Metot}

Özellikle metal işleme sektöründe kullanılan kesme sıvıları çevreye ve operatöre dermatit, havayolu enfeksiyonu ve çeşitli olumsuz etkileri olduğu bilinmektedir [13]. Son yıllarda ekolojik üretim yöntemleri ve koşulları tercih edildiğinden ve sağlık açısında zararları klasik yağlara göre nispeten daha az olduğundan bitkisel esaslı kesme yağlarının kullanımında artışlar gözlenmiştir. Bu çalışmada kullanılan bitkisel esaslı baz kesme yağına ait özellikler Tablo 1'de yer almaktadır.

Tablo 1. Bitkisel Esaslı Yağ Özellikleri

\begin{tabular}{cl}
\hline Özellik & Değer \\
\hline Yoğunluk $\left(20^{\circ} \mathrm{C}\right)$ & $0,895 \mathrm{~g} / \mathrm{ml}$ \\
Parlama Noktas1 & $170{ }^{\circ} \mathrm{C}$ \\
Viskozite $\left(40^{\circ} \mathrm{C}\right)$ & $5 \mathrm{cSt}$ \\
\hline
\end{tabular}

Nanoakışkan hazırlamada baz sıvı olarak yağ, su veya EG yaygın bir şekilde kullanılmaktadır. Nanoakışkan hazırlamada, bir adım (1.step) veya iki adım (2.step) metotları tercih edilmektedir.

Bir adım metodu, nanopartiküllerin fiziksel buhar biriktirme (Physical Vapor Deposition-PVD) 
veya sıvı kimyasal yöntemle hazırlanan nanopartiküllerin nanoakışkan olarak sentezlenmesiyle elde edilme sürecidir. Bu metotla kurutma, depolama, taşınım ve nanopartiküllerin karışmasının önlenmesiyle, nanopartiküllerin topaklanması bertaraf edilirken, akışkanın stabilitesi arttırılmaktadır. Ancak bu yöntemle sadece düşük buhar basıncıyla uyumlu akışkanlar kullanılabildiğinden, yöntem yetersiz kalmakta ve maliyeti nispeten iki adım yöntemine göre fazla olmaktadir [3].

İki adım yöntemindeyse nanoakışkanlar baz sıvıya nanopartikül eklenerek hazırlanmaktadır. Basit bir yöntem olarak görünse de nanopartiküllerin baz sıvıya eklenme sürecinde mekanik, manyetik veya ultrasonik karıştırıcılar kullanılmaktadır [14]. Şekil 1'de bir adım ve iki adım yöntemlerini ifade eden şema bulunmaktadır.

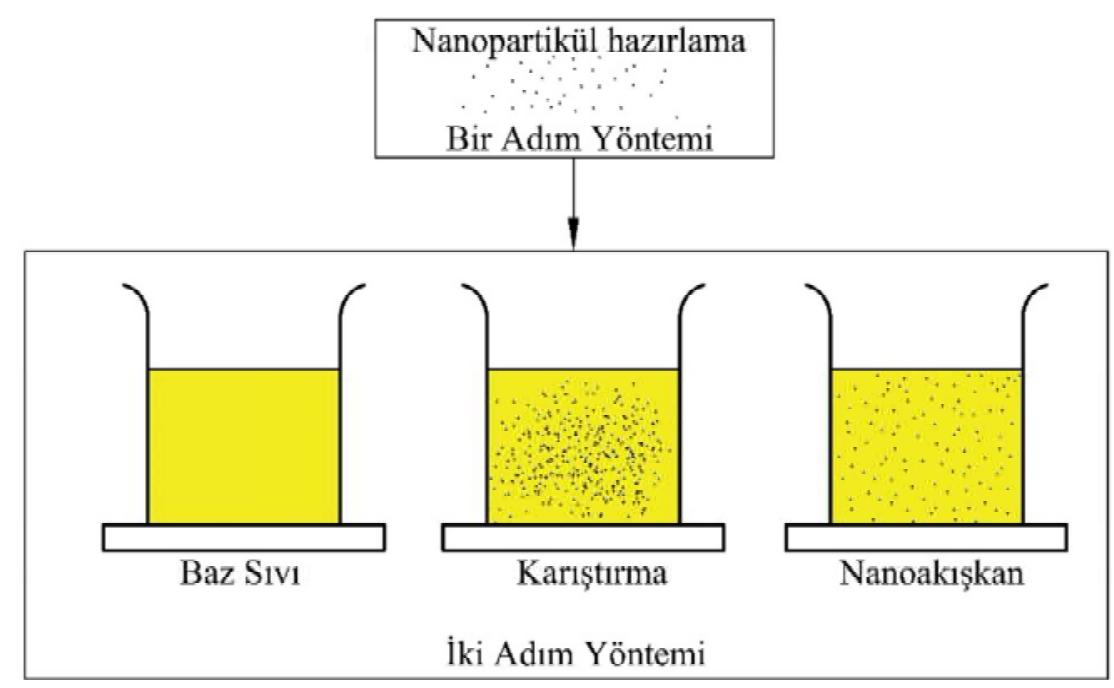

Şekil 1. Nanoakışkan Hazırlama Metotları [15]

Bu çalışmada maliyeti uygun olduğundan ve literatürde üzerinde daha fazla çalışma yapıldığından, iki adım yöntemi tercih edilmiştir. Ortalama $80 \mathrm{~nm}$ boyutlarında Grafit nanopartikülleri baz bitkisel esaslı yağ içerisine eklenerek nanoakışkanlar hazırlanmıştır. Grafit nanopartiküllerine ait ESEM görüntüleri ve EDX analizleri Şekil 2'de yer almaktadır.

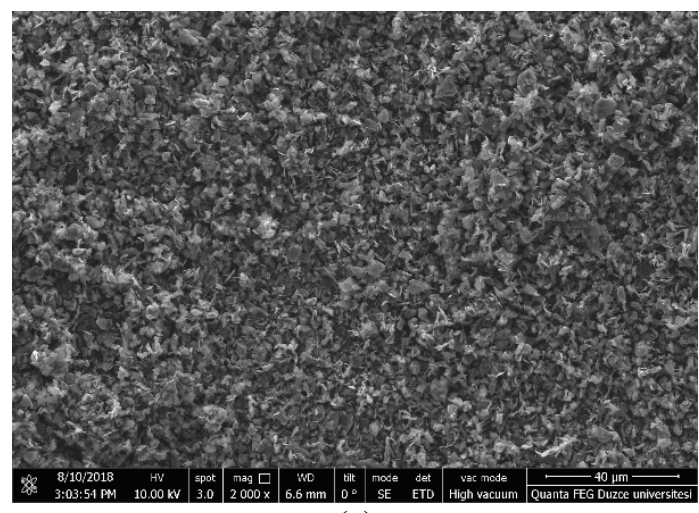

(a)

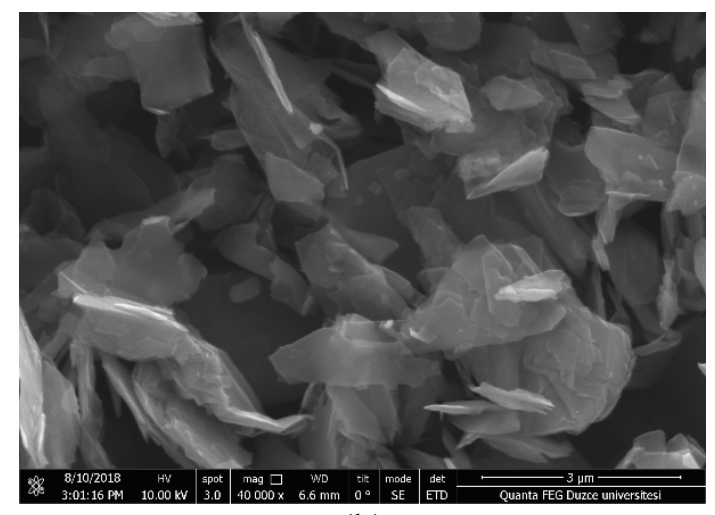

(b) 


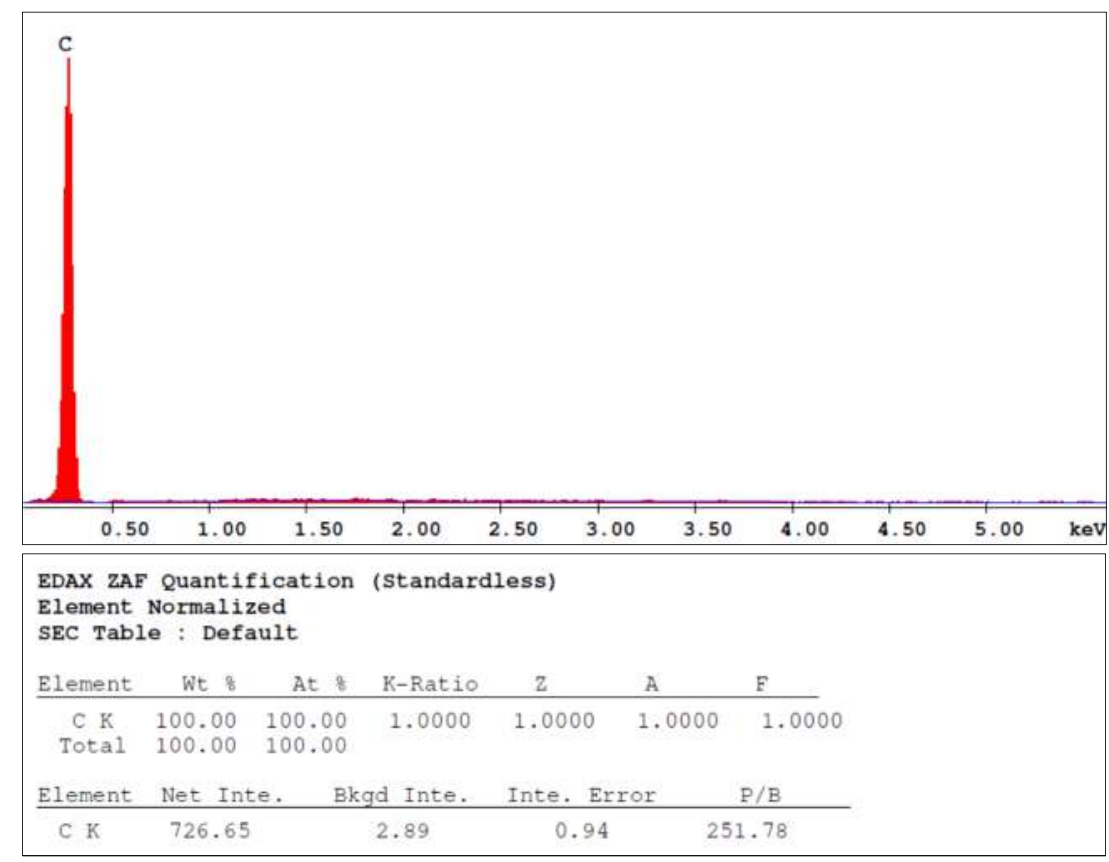

(c)

Şekil 2. Grafit ESEM a) 2000x büyütme grafit ESEM fotoğrafi, b) 40000x büyütme grafit ESEM fotoğrafi, c) Grafit malzeme EDX analiz sonuç görüntüsü

\subsection{Nanoakışkan hazırlama}

Nanoakışkanlar hazırlanırken dikkat edilmesi gereken en önemli süreç; baz sıvıya nanopartiküllerin eklenirken ortaya çıkan topaklanma, çökelme gibi olumsuz durumlardır. Bunun engellenebilmesi için yüzey gerilimini azaltıcı bazı kimyasallar eklenebilir [16]. Fakat eklenen bu kimyasallar eklendiği sıvının özelliğini bozabilmekte, yüksek sıcaklıkta özelliklerini değiştirebilmekte, sıvının saflığını etkileyebilmekte, köpük üretebilmektedirler veya termal direnç oluşturarak termal iletkenlikte bir azalmaya neden olabilmektedirler $[17,18]$. Bu gibi dezavantajlarından dolayı; bu çalışmada nanoakışkanlara yüzey gerilimini azaltıcı herhangi bir kimyasal eklenmemiş, yapılan deneysel çalışmalar üç farklı karıştırma işleminden geçerek, hazırlanan taze nanoakışkan karışımlarla gerçekleştirilmiştir.

İki adım yönteminde nanoakışkan elde ederken manyetik karıştırıcı, ultrasonik homojenizatör, ultrasonik banyo, mekanik karıştırıcı [14,19-20] vb. gibi farklı karıştırma teknikleri kullanılmaktadır. Bitkisel esaslı baz yağ içerisine hacimce $\% 0,25-0,50-0,75$ ve 1,00 oranlarında Grafit nanopartikülleri eklenerek nanoakışkanlar 5 aşamada hazırlanmıştır. 


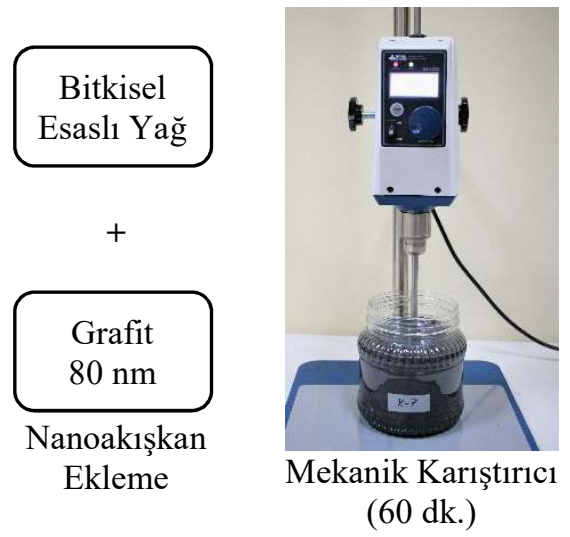

1. Adım

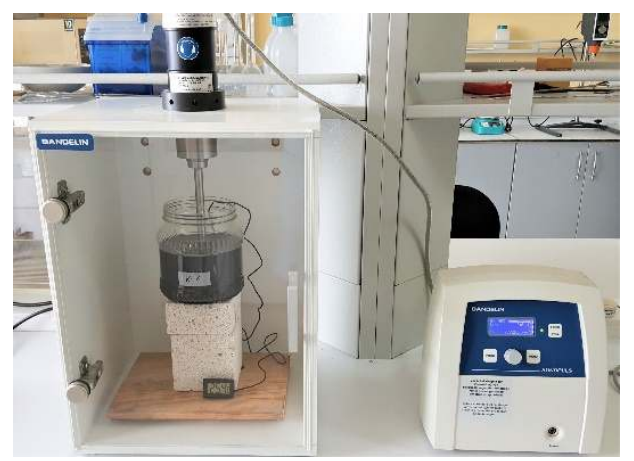

Ultrasonik Homojenizatör (30 dk.)

3. Adım

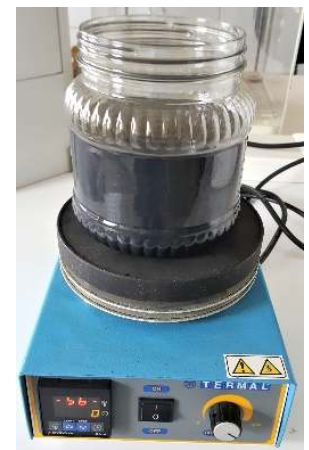

Manyetik Karıştırıcı $(120 \mathrm{dk}$.

4. Adım

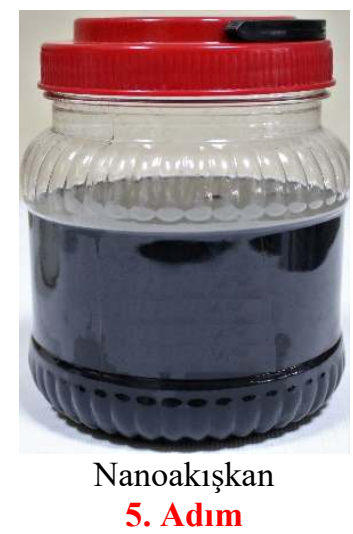

Şekil 3. Nanoakışkan Hazırlama Adımları

\subsection{Viskozite ve Termal iletkenlik ölçümü}

Su, yăg, EG gibi baz sıvıya eklenen nanopartiküller sayesinde oluşan nanoakışkanın, viskozite ve termal iletkenliğinin baz sıvıya göre daha yüksek olduğu bilinmektedir. Bu çalışmada ele alınan bitkisel esaslı kesme yağına hacimce $\% 0,25-0,50-0,75$ ve 1,00 oranlarında nano grafit partikülleri eklenerek hazırlanan nanoakışkanların, viskozite ve termal iletkenlikleri $30^{\circ} \mathrm{C}$ sıcaklıkta ölçülmüştür.

Baz sıvı (bitkisel esaslı kesme yağı) ve nanoakışkanların (dört farklı hacim oranı) viskozite ölçümleri Fungilab Premiuh H cihazla ölçülmüştür (Şekil 4-a). Nanoakışkanların ve bitkisel esaslı baz sıvının termal iletkenlikleri ise Hot Disk TPS 2500s cihazında ölçülmüştür (Şekil 4-b). 


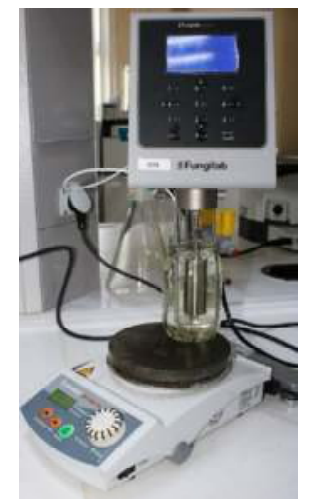

(a)

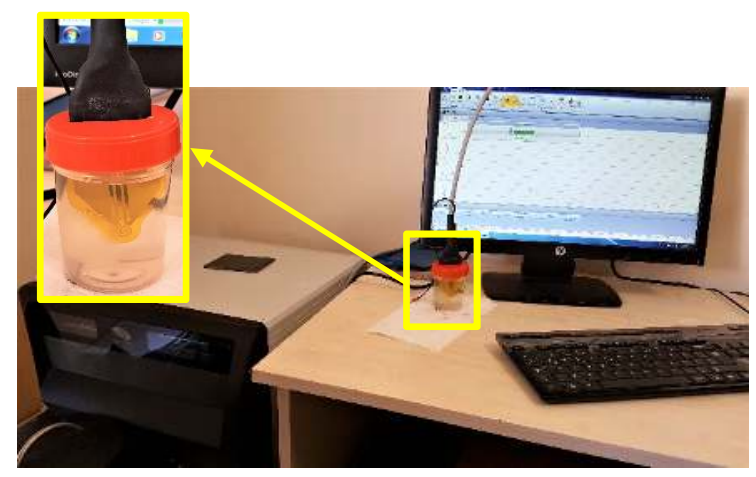

(b)

Şekil 4. a) Viskozite Ölçümü, b) Termal iletkenlik ölçümü

\section{Tartışma ve Sonuçlar}

\subsection{Viskozite ölçüm sonuçlarının karşılaştırılması}

Viskozite, nanoakışkanlar için en az termal iletkenlik kadar önem arz etmektedir. Fakat nanoakışkanların viskozitelerin incelenmesi üzerine yapılan çalışmalar, termal iletkenlik kadar fazla değildir. Nanoakışkan viskozitelerinin belirlenmesi üzerine bazı modeller (Brinkman, Wang ve ark., Gherasim ve ark., Pak ve Cho, Einstein) ve formüller bulunmaktadır. Nanoakışkanların viskozitelerine; nanopartiküllerin şekli (plak, silindirik, tuğla, yuvarlak vb.), eklenen nanopartiküllerin oranı (hacimce veya ağırlıkça), sıcaklık, nanopartiküllerin cinsi (metalik, oksit) vb. özellikler etki etmektedir [21].

Viskozite ölçümü için bu çalışmada deneysel yöntemle, viskozite tayin cihazı Fungilab Premium H (Şekil 4-a) kullanılmıştır. Hacimce \%0,25-0,50-0,75 ve 1,00 oranlarında nano grafit eklenerek homojen bir şekilde hazırlanan nanoakışkanların, viskozite ölçüm sonuçları Şekil 5'te yer almaktadir. 


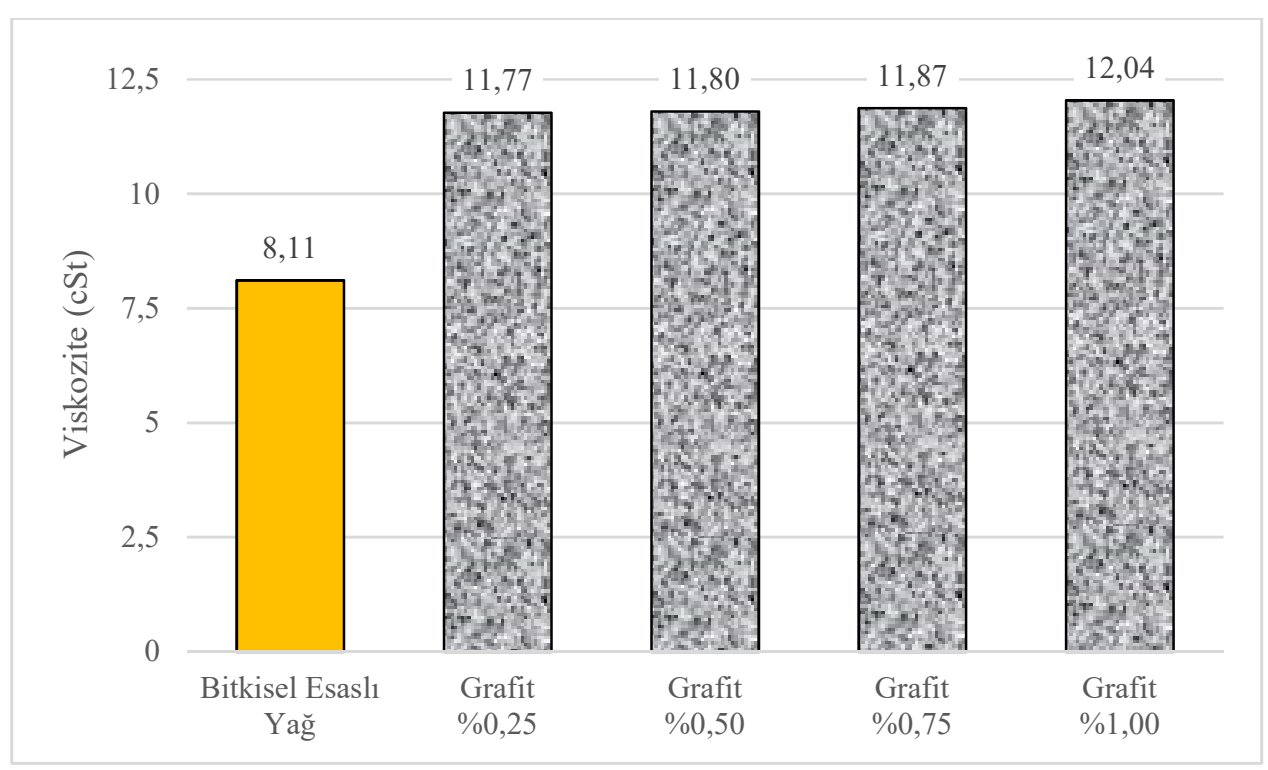

Şekil 5. Viskozite ölçüm sonuçları

Viskozite ölçüm sonuçlarına göre; bitkisel esaslı yağ içerisine hacimce eklenen nanopartiküller viskoziteyi arttırmışlardır. Ölçüm sonuçlarına göre baz sıvı (bitkisel esaslı yağ) viskozitesi 8,11 centistokes (cSt), hacimce \%0,25 grafit nanopartikül katkılı nanoakışkan viskozitesi $11,77 \mathrm{cSt}$, hacimce $\% 0,50$ grafit nanopartikül katkılı nanoakışkan viskozitesi $11,80 \mathrm{cSt}$, hacimce $\% 0,75$ grafit nanopartikül katkılı nanoakışkan viskozitesi 11,87, hacimce \%1,00 grafit nanopartikül katkılı nanoakışkan viskozitesi $12,04 \mathrm{cSt}$ olarak tespit edilmiştir.

Baz yağa eklenen; \%0,25 nano grafit ilavesi viskozitede yaklaşık \%45,1'lik artış sağlamıştır. $\% 0,50, \% 0,75$ ve $\% 1,00$ oranlarındaki grafit ilaveleri ise termal iletkenlikte sirasıyla $\% 45,5, \% 46,4$ ve $\% 48,5^{\prime}$ lik artış sağlamıştır. Dolayısıyla baz yağa eklenen en düşük orandaki nano grafit, baz yağa göre viskozitede kayda değer bir artış gösterirken, katkı oranlarının artmasıyla nano grafit ilavesinin viskozite değişimi üzerinde çok büyük etkiye sahip olmadığ görülmüştür. Katkı oranı $\% 0,25$ olan nanoakışkan referans alındığında; $\% 0,50, \% 0,75$ ve $\% 1$ grafit ilaveleri termal iletkenlikte sırasıyla $\% 0,25, \% 0,84$ ve $\% 2,29$ 'luk artışa sebep olmuştur.

\subsection{Termal iletkenlik ölçüm sonuçlarının karşılaştırılması}

Nanoakışkanlarda meydana gelen termal iletkenlikteki artış önemlidir çünkü nanopartiküllerin akışkanlara çok küçük yüzde oranıyla eklenmesiyle bile nanoakışkanın konvektif ısı transferde artışlar görülebilmektedir [22]. Su, yağ ve EG motorlar, nükleer sistemler, metal işleme sanayii, enerji üretimi ve tedariki ile birçok farklı alanda popüler termal iletim malzemesi olarak kullanılmaktadırlar. Termal iletkenlik ölçümünde çok farklı yöntemler (korumalı paralel plaka kullanarak kararlı durum yöntemi, geçici sıcak tel tekniği, geçici düzlem kaynağı (TPS) yöntemi vb.) kullanılarak ölçülebilmektedir [23].

Çalışmada ele alınan bitkisel esaslı kesme yağı talaşlı imalat endüstrisinde yaygın bir şekilde kullanılmaktadır. Bir kesme yağından beklenen temelde üç özellik vardır. İyi bir soğutma, yağlama 
ve kesme bölgesinden talaşların uzaklaştırılmasıdır. Kesme yağının iyi bir soğutma yapabilmesi için termal iletkenliğinin yüksek olması arzu edilir. Bu sebeple çalışmada baz sıvı olarak bitkisel esaslı kesme yağı ele alınmıştır. Bitkisel esaslı baz yağa hacimce üç farklı oranda grafit nanopartikül eklenerek farklı kontrasyonlarda nanoakışkanlar elde edilmiştir. Hazırlanan nano akışkanlara ait termal iletkenlik oranları Hot Disk TPS 2500 s cihazı kullanılarak $30^{\circ} \mathrm{C}$ sıcaklıkta ölçülmüştür. Ölçüm cihazında sıvı termal iletkenliği için tasarlanan 3,2 mm yarıçapında 5465 kodlu sensör kullanılmıştır. Sıvılara ait ölçüm sonuçları Şekil 6’da yer almaktadır.

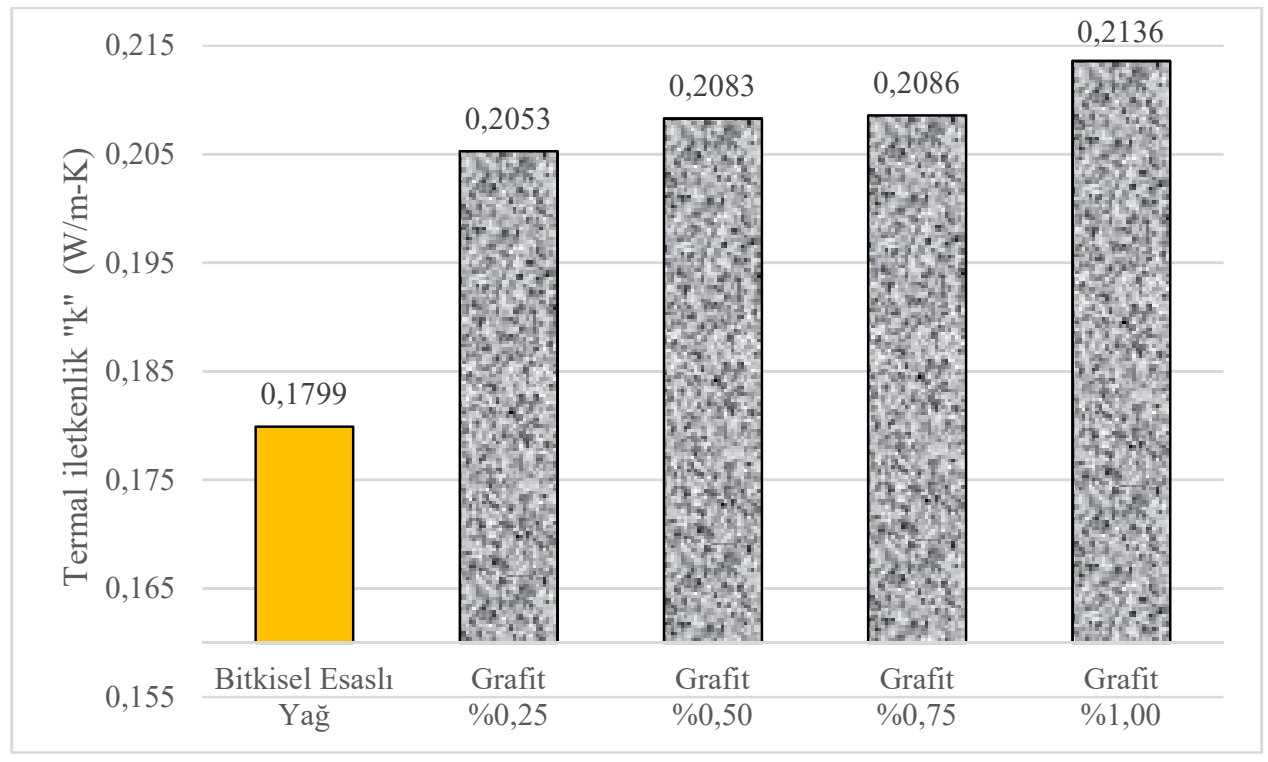

Şekil 6. Termal iletkenlik ölçüm sonuçları

Termal iletkenlik ölçüm sonuçlarına göre; çalışmada kullanılan bitkisel esaslı yağa eklenen grafit nanopartiküllerinin katkı oranları artıkça termal iletkenlik katsayısı da artmıştır. En düşük termal iletkenlik "k" baz yağda olurken $(0,1799 \mathrm{~W} / \mathrm{m}-\mathrm{K})$, en yüksek termal iletkenlik hacimce \%1,00 grafit nanopartikül katkılı nanoakışkanda $(0,2136 \mathrm{~W} / \mathrm{m}-\mathrm{K})$ olmuştur. Baz yağa eklenen; \%0,25 nano grafit ilavesi termal iletkenlikte yaklaşık \%14'lük artış sağlamıştır. $\% 0,50, \% 0,75$ ve \%1,00 oranlarındaki grafit ilaveleri ise termal iletkenlikte sırasıyla \%15,7, \%15,9 ve \%18,7'lik artış sağlamıştır. Dolayısıyla baz yağa eklenen en düşük orandaki nano grafit, baz yağa göre termal iletkenlikte önemli bir artışa neden olurken daha yüksek oranlarda nano grafit ilavesinin termal iletkenliğinin değişimi üzerinde çok büyük etkiye sahip olmadığı görülmüştür. Nitekim \%0,25 grafit ilavesi baz alındığında $\% 0,50, \% 0,75$ ve $\% 1$ grafit ilaveleri termal iletkenlikte sırasıyla $\% 1,4$, $\% 1,6$ ve \%4'lük artışa sebep olmuştur.

\section{Sonuçlar}

Bu çalışmada baz bitkisel esaslı yağa, ortalama $80 \mathrm{~nm}$ boyutlarında hacimce $\% 0,25-0,50,-0,75$ ve 1,00 oralarında grafit katılarak nanoakışkanlar hazırlanmıştır. Hazırlanan nanoakışkanların viskozite ve termal iletkenlikleri ölçülmüştür. Elde edilen sonuçlar aşağıdaki gibidir;

- Bitkisel esaslı yağa eklenen grafit nanopartikülleri 5 adımda (1.nanopartikül ekleme, 
2.mekanik karıştırma, 3.ultrasonik karıştırma, 4.manyetik karıştırma, 5.nanoakışkan) eklenerek nanoakışkanlar hazırlanmıştır.

- Hazırlanan nanoakışkanlar ve bitkisel esaslı baz yağın viskoziteleri ölçülmüştür. Ölçüm sonuçlarına göre; bitkisel esaslı yağa eklenen nanopartikül oranı artıkça, oluşan nanoakışkanın viskozitesi de artış göstermiştir. (Bitkisel esaslı yağ 8,11 cSt, \%0,25 grafitli nanoakışkan $11,77 \mathrm{cSt}, \% 0,50$ grafitli nanoakışkan 11,80 cSt, \%0,75 grafitli nanoakışkan $11,87 \mathrm{cSt}, \% 1,00$ grafitli nanoakışkan 12,04 cSt)

- Termal iletkenlik ölçüm sonuçlarına bakıldığındaysa, yine en düşük termal iletkenlik katsayı değeri " $k$ " (W/m-K) bitkisel esaslı yağda olurken, en yüksek termal iletkenlik katsayı değeri \%1,00 grafit katkılı nanoakışkanda olduğu görülmüştür. (Bitkisel esaslı yağ 0,1799 W/m-K, $\% 0,25$ grafitli nanoakışkan 0,2053 W/m-K, \%0,50 grafitli nanoakışkan 0,2083 W/m-K, \%0,75 grafitli nanoakışkan 0,2086 W/m-K, \%1,00 grafitli nanoakışkan 0,2136 W/m-K)

- Sonuçlar genel olarak değerlendirildiğinde, bitkisel esaslı baz yağa eklenen grafit nanopartiküllerinin eklenmesiyle hem viskozite hem de termal iletkenlikte artışa neden olduğu, katkı oranlarının artmasıyla hem viskozite hem de termal iletkenlikte artışın sınırlı kaldığ1 tespit edilmiştir.

\section{Teşekkür}

$\mathrm{Bu}$ çalışma Düzce Üniversitesi Bilimsel Araştırma Projeleri Destek Programı kapsamında desteklenmiştir. Proje Numarası: 2017.07.04.593

\section{Kaynaklar}

[1] Özerinç, S., Kakaç, S., \& Yazıcıoğlu, A. G. Enhanced thermal conductivity of nanofluids: a state-of-the-art review. Microfluidics and Nanofluidics, 20108;(2);145-170.

[2] S. Lee, S.U.S. Choi, S. Li, J.A. Eastman. Measuring thermal conductivity of fluids containing oxide nanoparticles, J. Heat Trans.-T. ASME 121, 1999;280-289.

[3] Li, Y., Tung, S., Schneider, E., \& Xi, S. A review on development of nanofluid preparation and characterization. Powder technology 2009;196(2);89-101.

[4] K.J. Lee, S.-H. Yoon, J. Jang. Carbon nanofibers: a novel nanofilter for nanofluid applications, Small 3, 2007;1209-1213.

[5] H. Xie, J. Wang, T. Xi, Y. Liu, F. Ai, Q. Wu. Thermal conductivity enhancement of suspensions containing nanosized alumina particles, J. Appl. Phys. 91, 2002;4568-4572.

[6] W. Yu, H. Xie, Y. Li, L. Chen, Q. Wang. Experimental investigation on the thermal transport properties of ethylene glycol based nanofluids containing low volume concentration diamond nanoparticles, Colloids Surf. 2011; A 380;1-5.

[7] M. Pastoriza-Gallego, L. Lugo, J. Legido, M. Piñeiro. Thermal conductivity and viscosity measurements of ethylene glycol-based $\mathrm{Al}_{2} \mathrm{O}_{3}$ nanofluids, Nanoscale Res. Lett. 2011;6;(1);221.

[8] M. Ghanbarpour, E.B. Haghigi, R. Khodabandeh. Thermal properties and rheological behavior of water based $\mathrm{Al}_{2} \mathrm{O}_{3}$ nanofluid as a heat transfer fluid, Exp. Thermal Fluid Sci. 2014;53 (0);227-235.

[9] G. Zyla, J. Fal, P. Estelle. The influence of ash content on thermophysical properties of ethylene glycol based graphite/diamonds mixture nanofluids, Diamond \& Related Materials, 
2017;74;81-89.

[10]E.B. Elçioğlu, A.G. Yazıcıoğlu, S. Kakaç. Nanoakışkan Viskozitesinin Karşılaştırmalı Değerlendirmesi, Isı Bilimi ve Tekniği Dergisi, 2014;34;1;137-151.

[11] Talib, N., \& Rahim, E. A. Performance of modified jatropha oil in combination with hexagonal boron nitride particles as a bio-based lubricant for green machining. Tribology International, 2018;118;89-104.

[12] Tavman, I., Turgut, A. An Investigation on thermal conductivity and viscosity of water based nanofluids, Microfluids Based Microsystems, NATO Science for Peace and Security Series A: Chemistry and Biology, 2010;0;139-162.

[13] Sharma, A. K., Tiwari, A. K., \& Dixit, A. R. Effects of Minimum Quantity Lubrication (MQL) in machining processes using conventional and nanofluid based cutting fluids: A comprehensive review. Journal of cleaner production, 2016;127;1-18.

[14]Liu, M. S., Lin, M. C. C., Huang, I. T., \& Wang, C.C. Enhancement of thermal conductivity with carbon nanotube for nanofluids. International communications in heat and mass transfer, 2005;32(9);1202-1210.

[15] Sharma, S. K., \& Gupta, S. M. Preparation and evaluation of stable nanofluids for heat transfer application: a review. Experimental Thermal and Fluid Science, 2016;79;202-212.

[16]Devendiran, D. K., \& Amirtham, V.A. A review on preparation, characterization, properties and applications of nanofluids. Renewable and Sustainable Energy Reviews, 2016;60;21-40.

[17] Nasiri, A., Shariaty-Niasar, M., Rashidi, A., Amrollahi, A., \& Khodafarin, R. Effect of dispersion method on thermal conductivity and stability of nanofluid. Experimental thermal and fluid science, 2011;35(4);717-723.

[18]Wang, J. J., Zheng, R. T., Gao, J. W., \& Chen, G. Heat conduction mechanisms in nanofluids and suspensions. Nano Today, 2012;7(2);124-136.

[19] Wusiman, K., Jeong, H., Tulugan, K., Afrianto, H., \& Chung, H. Thermal performance of multi-walled carbon nanotubes (MWCNTs) in aqueous suspensions with surfactants SDBS and SDS. International Communications in Heat and Mass Transfer, 2013;41, 28-33.

[20] Manimaran, R., Palaniradja, K., Alagumurthi, N., Sendhilnathan, S., \& Hussain, J. Preparation and characterization of copper oxide nanofluid for heat transfer applications. Applied Nanoscience, 2014;4(2);163-167.

[21] Alawi, O.A., Azwadi, N., Sidik, C., Xian, H.W., Kean, T.H., \& Kazi, S.N. Thermal conductivity and viscosity models of metallic oxides nanofluids, International Journal of Heat and Mass Transfer, 2018;116;1314-1325.

[22] S.M.S. Murshed, K.C. Leong, C. Yang, A combined model for the effective thermal conductivity of nanofluids, Appl. Therm. Eng. 29;2009;2477-2483.

[23] Harris, A., Kazachenko, S., Bateman, R., Nickerson, J., \& Emanuel, M. Measuring the thermal conductivity of heat transfer fluids via the modified transient plane source (MTPS). Journal of Thermal Analysis and Calorimetry, 2014;116(3);1309-1314. 